\title{
THE INVOLVEMENT OF MEDIATION IN FAMILY COUNSELING: A COMPARATIVE STUDY BETWEEN THE NORWEGIAN AND THE INDIAN SYSTEMS
}

\section{Geeta Appachu*}

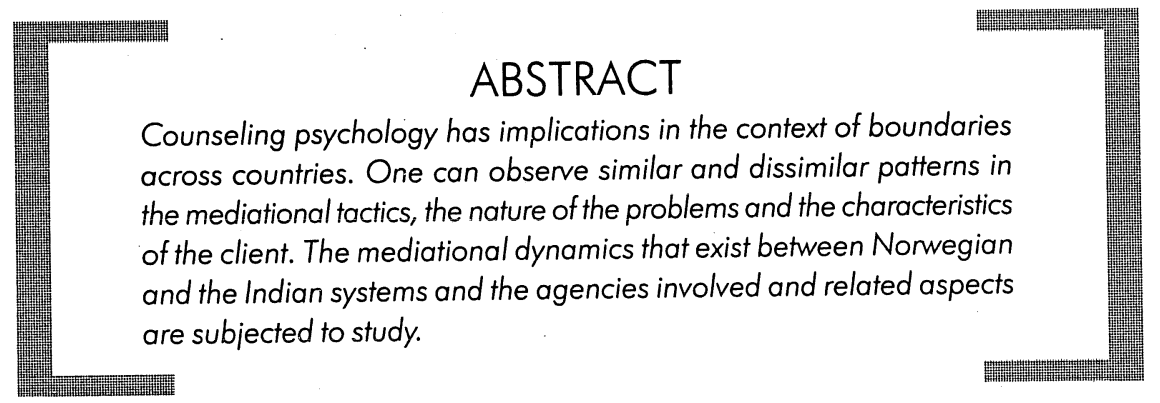

\section{Introduction}

Family therapy has grown dramatically in popularity in recent years. The concept of family structure may be defined as the organized pattern in which family members interact. The subsystems may contain any number of people within the family and subsystems groupings may be determined by age, generation, gender interests and so forth.

* Department of Post Graduate Studies in Psychology, Christ College, Bangalore-560029.e-mail:geetaka03@yahoo.co.in 
Research on family and couples counseling may be divided into two kinds: Process research and Outcomes research. The data findings on the process of family and couples counseling - what leads to what within the session are significant. The treatment outcomes are complex and multitudinal. It ranges from perfect union to estranged separation.

In marital disharmony, mediation by a third party on a center, exercises an important role in finding an answer to the problem being confronted by the spouses. The confounded problem can only be unraveled by an expert - a mediator who is able to view the problem from different angles and from a frame of reference that is objective and detached.

The mediator projects a realistic view of the problem. It has been found that in a majority of family crises, the members do not have a clear view of the state of affairs and when the members start finding fault with others or use ego defense mechanisms, the mediators are able to control the problem from being blown out of proportion.

A mediator works between partners in order to arrive at a common agreement regarding their relationship. The absence of agreement in vital issues, unity in common matters and divergence of interests between the partners force the situation to a critical point. At this juncture the mediator steps in to settle and to find an acceptable solution to the problem.

The purpose of mediation is to enable parents to arrive at an agreement concerning parental responsibility, right to custody of the child in the case of separation and where the child is to live permanently. In the process of mediation, all the important facts and complex issues regarding the marital conflict and more importantly the future of the children and the inheritance of the earned income and the future payment have to be sorted out and amicably settled.

The importance of mediation is that the mediation does not force a solution on the conflicting members. The mediator explores different avenues to a comfortable solution and indicates the way to a harmonious life. The final decision must be taken by the persons in conflict.

\section{General Mediational Mechanisms}

The process of mediation differs on a number of procedures and ways. The following are some of the strategies used by mediation experts. 


\section{Active Discussion}

In this process, the mediator initiates and sustains an active discussion process. This in depth discussion is carried out by the conflicting persons and is presided by the mediator. A kind of centering takes place in which the problem and issues surrounding it are brought fonward. The outcome of the active discussion is problem centering and an acceptable solution.

\section{Spontaneous Unguided Explorations}

The spouses are given a free hand to express themselves without hindrances or inhibitions. Spontaneity is the characteristic of this freewheeling. The mediator who has assumed the role of an observer notes down the implications and contents and the expressed views. The primary purpose of this strategy is to see the nature of the problem, the extent of insight of the couple and how far they are reciprocal and accommodative.

\section{Content-by-Content Consideration}

In this mechanism, the mediator explores the problem content-wise. He identifies and arranges the problem in terms of priorities. The views of the parties are invited and a solution is reached at the end.

\section{Balancing Act}

The mediator holds the key of expression of emotion and verbal statements. To conclude successfully, it is necessary for the mediator to allow or not, the expression of anger and speech. It has to be artfully managed by the mediator. In the balancing act, sufficient time is allowed for dissipation of high intensity emotion and the mediator will take up the problem confessed.

\section{Tow-sided Vs. One-sided Disclosure}

In this mediation strategy, the mediator brings the issue and problem to the open using a two-sided or a one-sided description. In the former, both the conflicting persons discuss the issue. The mediator's role is to make clear the reasonable and unreasonable elements in the disclosure of the problem. In the one-sided approach, the mediator first listens to the views of a person and then the views of the second person. In this way after finding the common threads in both the persons' views, the mediator is able to bring both the persons to the same forum.

\section{Mediation Styles}

The well-known conflict-resolution styles (Hellreiegel, Slocum and Woodman, 2001) maybe used as a strategy in the mediational process. The two dimensional variables in the strategy may be changed to suit the mediational situation and the problem faced by the mediator. The assertiveness and cooperativeness are changed into 
severity of the problem and the willingness and the consent of the partners for an effective mediation. A third dimension, the effectiveness and personal qualities of the mediator may be added to it. The two diagrams explaining the dynamics of the strategy are given, at the end.

\section{Accommodating Style}

It is a strategy that demands submission to the wishes of others. One of the couples may be persuaded to accept the demands of another. It becomes a selfless act on the part of one of the partners.

\section{Avoiding Style}

When the severity of the problem is low and the consent is minimum, the mediator can stay away from the contending issues as long as the persons are not committed.

\section{Collaborative Style}

Here the mediator desires to maximize joint results, the mediator tries to convince the couples that conflict is a natural life process, helpful and leads to a renewal of life.

\section{Compromising Style}

The mediator seeks compromising behaviors from the persons because of the inadequacy of the situation. The persons are made to give up certain demands for the common good.

\section{Effectiveness Dimension}

The effectiveness of the mediation and the mediation strategy depends on the situation presented. The situational characteristics decide the strategy to be adopted.

\section{The Stages of Mediation}

In the initial stage of mediation, a meeting with the spouses is arranged to assess the dynamic nature of the relationship between the conflicting partners and to explain them what they can expect from the mediational efforts.

In the second stage of mediation, the time of meeting is set, ground rules are laid, the procedure of conduct are fixed and the mutually agreed goals are set for the person to achieve. The mediator decides upon the specificity to be adopted in his effort to achieve set goals, taking into account the reality.

In the third stage, the information gathering stage, the documentation for property assets and debts are prepared. All the relevant facts concerning separation are 
obtained. All the key aspects relating to the termination of relationship come to the aid of mediation.

In the fourth stage, the counselor helps the partners to cope with the emotional difficulties. They will be counseled as to the exact nature of the problem and the difficulties ahead. They will be provided with a clear vision so that they understand the nature of the problem in their own way. An unbiased objective approach will enable them to overcome the difficulties in the relationship.

\section{The Norwegian System}

\section{The Concept and Structure of Mediational Agencies}

In the Norwegian governance, the County Department of Family and Social Affairs establishes the centers and funds the administration. The centers are established based on the needs of the population. There are more than 60 family care centers. The centers become an active department of the government. The administration has full responsibility of family care and child care agencies.

The concept of these centers is to help families in crisis, to bring partners in conflict and provide support and guidance, help in mediating conflicts between parents and teenage children, and other services for personal problems within families. The main focus is on the parents to bring a positive solution for the children and family.

The agency functions with one psychologist, four social workers and some parttime social workers. There are psychiatrists who render service only when requested by the center. Besides, there is a child care consultant who is also available on request.

\section{Training and Responsibilities of the Staff}

The staff of the counseling agency is given family therapy education. It is a 2 year program followed by supervised clinical education. It is a thorough program that equips the staff with the methods and techniques of family therapy.

It is observed that by and large, couples approach the clients towards the end of their relationship. These centers help the couple to work towards a positive relationship or seek marital separation. In either case, it is the responsibility of the staff to see that their emotional adjustment difficulties are overcome. The potential of the client are pointed out by the therapist so that they get a correct view of the problem. In this sense it tends towards the non-directive approach. 
The center registered 373 cases and approximately 160 cases for mediation. 57\% of these are for working a better relationship, $35 \%$ are with parent-child problems; $2.5 \%$ is with the problems that children brought forward about the parents and other family members; and $4.5 \%$ of the cases are with other specific problems.

\section{Characteristics of the Client}

The Norwegian Society is comprised of individualists as opposed to individuals with a collective mentality and relational orientation. It is this independent orientation and self-reliance that makes the couple approach the clients towards the end of their relationship; couples were either egoistical or diffident.

It is observed that $50 \%$ of the Norwegian population has conflicts in marriage or relationship. One third of the population visits and uses the services offered by these centers.

Common problems seen are total lack of communication among couples, sexual problems, disagreement with time and responsibility at home, unfaithful partners. Family violence, alcohol abuse, serious illness with one of the spouse and a trend with increasing numbers of gamblers. The age range of the population who seek the services of these centers is within 25-40 years of age. More than $90 \%$ of these couples have children.

\section{The Importance of Mediation}

Mediation is one of the important responsibilities of the centers. Mediation has a significant role to play in clearing the misgivings and hostility prevailing in the midst of the people.

All family counseling centers provide mediation. The process and strategies of mediation differs across situations and problems. The centers face problems with couples who are immune to mediation, who are defiant and may not reach an agreement. They may not allow mediation to work in their marriage.

Family counseling agencies provide advice and assistance to parents who wish to establish agreements concerning their children. The law supports by hearing 12-18 year children in a divorce hearing.

When parents have reached an agreement the mediation issues a certificate of mediation. 


\section{Family Counseling in the Indian Context}

While the concept of mediation continues to be the same and the aim and the process are similar, the agencies established and the structure created to provide the facilities for the clients are not the same. There are no centers directly administered by the government. Non-governmental Organizations are active in the field. Besides social and voluntary organizations, private agencies and psychiatric hospitals provide the services. These are centers which are run by religious and charity organizations that provide the services free of cost.

While there are no specific mediational agencies engaged in the task of bringing about amiable solutions to the estranged husband and wife, the marital counseling centers shoulder the responsibility of mediation and the procedures of separation.

There is no systematized training imparted for mediation agencies. The process of mediation is part of family counseling in India. Those trained in family therapy automatically becomes eligible for mediation. The family therapists by and large are hesitant to work towards separation, they stop short of separation. In extreme cases the therapist prepares the setting for separation including the case of the child.

It can be seen from the comparison that both the systems have much in common and that the counseling agencies play an effective role in setting and resolving family conflicts and effecting separation of couples on the brink of personal disaster. The dissimilarities in the two modes are clearly visible in the agencies established to provide counseling, the training of the family therapists and the responsibilities of the counselor. The characteristics of the client also show a distinct pattern, and finally the mediational outcomes also differ. The Nonwegian system paves the way for clear separation and the Indian system pampers the client to the extent on rebuilding broken relationships. 


\section{A Comparison Between the Norwegian and Indian System}
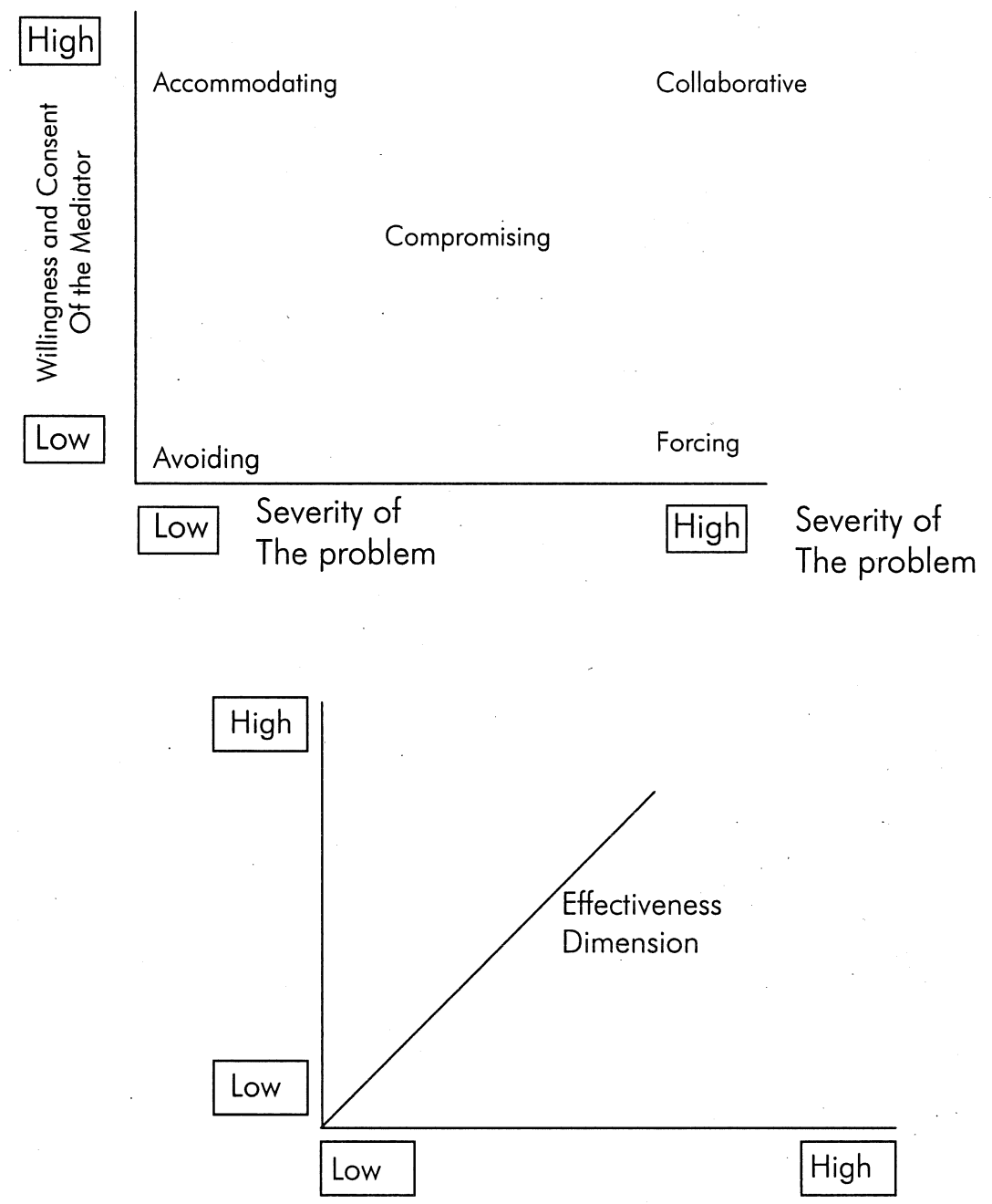


\section{A Comparison Between Norwegian and Indian System}

\section{Norwegian \\ System}

Mediator works between partner in order to arrive at a common agreement regarding the relationship and most importantly the custody of children

Counseling agencies administered by the government

Systematic training of the staff in family counseling

Provides target specific counseling to clients

Communication problems, sexual problems, unfaithful partners, family violence, alcohol abuse

Mediational strategies culminating in separation
Indian

System

Mediator works between partners in order to arrive at a common agreement regarding the relationship and most importantly the custody of children

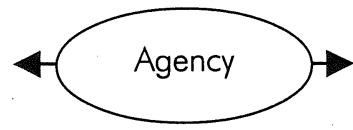

Non-Governmental organizations, private agencies, family courts

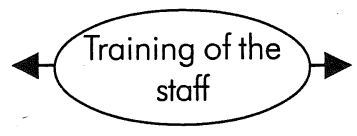

Training part of the Family counseling - non systematic

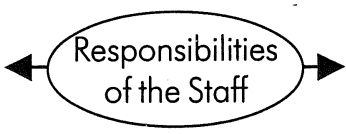

Provides non specific marital counseling

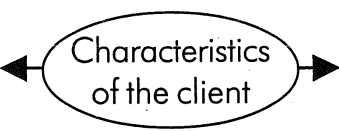

Infidelity, problems in relationship, alcohol, problems of the in-laws, dowry, illness

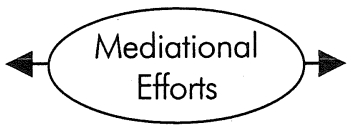

Mediational strategies aimed at psychological changes. Separation is done by family courts

\section{Conclusion}

Family counseling has not clearly evolved in the Indian context and it continues to be a part of general counseling. There are various agencies functioning with the label marital counseling, couples counseling, etc, but there is no established regulated system that takes care of all the diverse needs of a broken family or family and 
marriage that is in crisis. Voluntary and religious organizations satisfy some of the needs of the family and marriage crisis. Those agencies have to be converted into effective social instruments.

\section{Acknowledgements}

This observational study was possible because of very clear and detailed explanations of the history and functioning of the center by its director, Inger.

Special mention of thanks for supporting and encouraging the project is to Mrs. Sigrun Witso.

The project is a reality for all the efforts of supporting and translating during the interview by Ms. Marte Knutsson.

\section{References}

Gelso, C.J and Fretx, B.R (1995) Counselling Psychology, Prism Books; Bangalore.

Hellxiegel, D, Slocum, J. W and Woodman, R.W (2001) Organizational Behavior. Southwestern; US.

Heresy, P and Blanchand, K.H (1996) Management of Organizational Behavior. Prentice Hall of India Prt. Ltd.

Weiss, J.W (2001) Organizational Behavioral Change. Vikas Publishing House, New Delhi. 